\title{
Estudio comparativo del sellado de catéteres con citrato trisódico o heparina sódica más gentamicina
}

Premio Izasa. Accesos vasculares y nuevas tecnologías

\section{A. Baltrons Bosch - S. Coll Vinyoles - C. Font Senen - M. Jubany López - C. Plana Illa - A. Sunyer García}

\section{Servicio Hemodiálisis Clínica Girona. Girona}

\section{RESUMEN}

La cateterización de una vena central como acceso vascular para la hemodiálisis supone una alternativa rápida y segura, que permite ser utilizada inmediatamente y obtener flujos sanguíneos óptimos. Sin embargo, el uso de catéteres no está exento de complicaciones, lo que provoca una alta morbilidad aumentando las cargas de trabajo y el gasto económico.

La colonización y la formación de una película producida por las bacterias (biofilm) son considerados factores de riesgo, tanto en las infecciones relacionadas con catéter como en trombosis intraluminal. Para reducir estas complicaciones, utilizábamos como profilaxis un protocolo de sellado en los catéteres con una solución de heparina al $5 \%$ más gentamicina. Sin embargo, debido a complicaciones hemorrágicas, infecciosas y a una exposición constante del paciente a antibióticos, se decidió cambiar de protocolo a una solución de citrato trisódico concentrado $(46,7 \%)$ por sus propiedades anticoagulantes y antimicrobianas.

\section{Correspondencia:}

$\mathrm{M}^{\mathrm{a}}$ Carme Font

C/ Lorenzana, 36 - 17002 Girona menxufont@yahoo.es
Nuestro objetivo es valorar la implantación de un protocolo con citrato trisódico concentrado para el sellado de los catéteres. Los resultados obtenidos en este estudio son: importante descenso en el número de infecciones; menor número de manipulaciones; menor utilización de antibióticos, evitando crear resistencias y sensibilizaciones; dosis dialítica adecuada, disminución del coste económico de las cargas de trabajo y de la morbilidad de los pacientes.

PALABRAS CLAVE:

- CATÉTER VENOSO CENTRAL

- CITRATO TRISÓDICO

- DISGEUSIA

Comparative study of catheter sealing with trisodium citrate or sodium heparin plus gentamicin

\section{Abstract}

Placing a catheter in a central vein as vascular access for haemodialysis is a quick and safe alternative that can be used immediately and lets optimal blood flows be obtained. However, the use of catheters is not free from complications, causing high morbility and increasing the work load and economic cost. 
The colonization and formation of a film produced by bacteria (biofilm) are considered risk factors, both in infections related to the catheter and in intraluminal thrombosis. To reduce these complications, we used a catheter sealing protocol with a $5 \%$ heparin solution plus gentamicin. However, due to haemorrhagic complications, infections and a constant exposure of the patient to antibiotics, it was decided to change the protocol to a concentrated $(46.7 \%)$ trisodium citrate solution because of its anticoagulant and antimicrobial properties.

Our aim is to evaluate the implementation of a protocol with concentrated trisodium citrate for sealing catheters. The results obtained in this study are: important fall in the number of infections; less handling; less use of antibiotics, preventing the creation of resistance and sensitivities; adequate dialytic dose, reduction in economic cost of work load and in patient morbility.

\section{KEY WORDS}

\section{- CENTRAL VEIN CATHETER \\ - TRISODIUM CITRATE \\ DYSGEUSIA}

\section{Introducción}

El aumento progresivo de pacientes en hemodiálisis con edad avanzada y de patología vascular asociada ha hecho que muchos de ellos sean tributarios de acceso vascular a través de un catéter venoso central (CVC). Sin embargo, a pesar de utilizar los protocolos establecidos para su manipulación, presentan principalmente dos grandes causas de disfunción: la trombosis y la infección.

La agregación plaquetaria y los depósitos de fibrina son la mayor causa de oclusión. La trombosis ya sea intraluminal, o por formación de vaina de fibrina representa el $40 \%$ de la disfunción de los catéteres. Su tiempo de aparición oscila entre 73 y 84 días.

La colonización y la formación de un biofilm producido por las bacterias, son consideradas grandes factores de riesgo, tanto en las infecciones relacionadas con el catéter como en la trombosis intraluminal. La infección inmediata relacionada con la colocación del catéter o bien tardía por la manipulación de este, es la complicación más frecuente y grave de los CVC y suele ser la causa principal de retirada.

La solución de citrato trisódico de alta concentración está descrita como una sustancia de sellado para catéteres por su amplio espectro antimicrobiano, y como anticoagulante efectivo, dado que es un potente antitrombótico. Actúa como quelante de los cationes divalentes $\mathrm{Mg}^{2+}$ y $\mathrm{Ca}^{2+}$. La quelación de $\mathrm{Mg}^{2+}$ puede interferir en la integridad celular degradando la membrana de la pared celular bacteriana. El $\mathrm{Ca}^{2+}$ podría regular varios genes responsables del crecimiento y supervivencia de los microorganismos. La formación de biofilm es probablemente dependiente de $\mathrm{Ca}^{2+}$. El citrato trisódico como anticoagulante actúa ligando el factor $\mathrm{Ca}^{2+}$, extrayéndolo de las enzimas del sistema de coagulación.

Los efectos indeseables que pueden aparecer como consecuencia de la utilización de esta sustancia son: disgeusia y parestesias. Estos efectos desaparecen en un minuto y son signo de haber introducido un exceso de solución con demasiada rapidez.

Describimos aquí nuestra experiencia con el uso de citrato trisódico al $46,7 \%$ como método de sellado de los catéteres, tanto temporales como permanentes, utilizado durante el año 2006 comparándolo con los catéteres sellados con una solución de heparina sódica al $5 \%$ más gentamicina de $5 \mathrm{mg} / \mathrm{ml}$ durante todo el periodo del 2005, según protocolo que veníamos utilizando en nuestro servicio.

\section{Objetivos}

\section{Nuestros objetivos son los siguientes:}

1. Evaluar el uso de citrato trisódico al $46,7 \%$ como método de sellado de todos los catéteres, valorando el rendimiento de éstos, la adecuación de la hemodiálisis y los efectos secundarios del fármaco, así como la tasa de infecciones del catéter.

2. Comparar la disfunción y las infecciones de todos los catéteres con el sellado del citrato trisódico y de la heparina sódica al 5\% con gentamicina 


\section{Material y Métodos}

Realizamos un estudio retrospectivo y comparativo en el que fueron incluidos todos los pacientes portadores de catéter durante 2 años. Se revisó una muestra de 42 pacientes de los cuales 17 son hombres y 25 mujeres con edades comprendidas entre 24 y 89 años; 19 llevaban catéter percutáneo temporal y 24 Ilevaban catéter tunelizado permanente.

El primer grupo estudiado durante el año 2005 utilizó como sellado heparina sódica al $5 \%$ con gentamicina $5 \mathrm{mg} / \mathrm{ml}$ en la luz del catéter, según protocolo. La muestra constaba de 20 pacientes, de los cuales 8 Ilevaban catéter percutáneo temporal y 12 catéteres tunelizados permanentes. No se excluyó a ningún paciente.

El segundo grupo estudiado durante el año 2006 utilizó como sellado el nuevo protocolo con citrato trisódico de alta concentración (46,7\%). La muestra constaba de 22 pacientes, 11 de ellos con catéter percutáneo y 11 con tunelizado permanente. Se excluyó a 1 solo paciente por disfunción temprana (portador de 4 catéteres en 1 mes) por mala posición.

La obtención de los datos se recogió de las historias clínicas de los pacientes y de las gráficas de enfermería. Se realizó una revisión bibliográfica sobre la utilización del citrato trisódico como solución de seIlado, aplicando el procedimiento según protocolo del fabricante.

Analizamos en el grupo sellado con citrato diferentes parámetros que indican buena calidad dialítica a través de la mediana de sus parámetros ya que por la pluripatología de un paciente obtenemos valores atípicos respecto a los restantes y por este motivo no podemos utilizar la media. Los parámetros analizados son los siguientes: el KTV, la hemoglobina, la PCR, el fósforo, la albúmina y el tiempo de tratamiento (en minutos). Para calcular el flujo de sangre, las presiones arteriales y venosas del monitor hemos aplicado la media en cada tratamiento.

En los dos grupos registramos las distintas manipulaciones realizadas que son las siguientes: los cambios posturales, los catéteres invertidos, los lavados con suero, la utilización de uroquinasa y también los que no necesitaron manipulación. Anotamos todos los problemas que iban surgiendo, especialmente las trombosis y las infecciones tanto locales (orificio de entrada) como sistémicas, además de los bajos flujos y los efectos indeseados derivados de la sustancia utilizada como sellado (sangrado, parestesias y disgeusia).

\section{Resultados}

\section{Perfil de la muestra}

En el presente estudio han intervenido 42 pacientes de los cuales, 17 son hombres y 25 mujeres con edades comprendidas entre 24 y 89 años; 19 de los pacientes llevaban catéter percutáneo temporal y 24 llevaban catéter tunelizado. Fueron sellados 20 catéteres con heparina al $5 \%$ más gentamicina $5 \mathrm{mg} / \mathrm{ml}$ del lumen y 22 catéteres con citrato trisódico de alta concentración $(46,7 \%)$.

\section{Disfunción del catéter}

Se estudiaron los problemas de disfunción del catéter analizando diferentes parámetros (figura 1): de los 22 pacientes del grupo de citrato, 7 (31,82\%) pacientes no tuvieron problemas, y de los 15 (68,18\%) restantes, $8(36,36 \%)$ casos fueron posturales, 1 $(4,55 \%)$ presentó disfunción por fibrina, 1 (4,55\%) se trombosó, $5(22,73 \%)$ con bajo flujo.

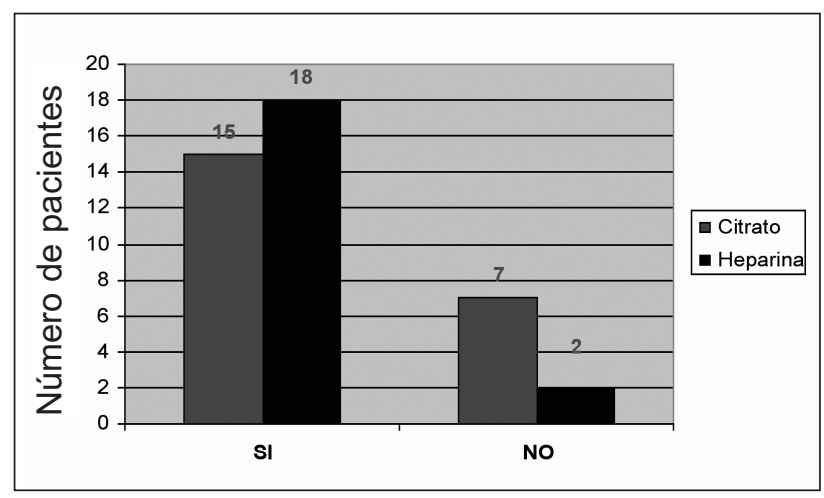

Figura 1. Problemas de flujo

De los 20 catéteres sellados con heparina Na más gentamicina, 2 (10\%) no tuvieron problemas de flujo, y de los 18 (90\%) restantes, 6 (30\%) precisaron 
cambios posturales, 6 (30\%) tuvieron bajo flujo, 5 (25\%) presentaron disfunción por fibrina y 1 (5\%) con sangrado del orificio.

Cuando se analizaron las diferencias de presión venosa y arterial del monitor en los dos grupos, no se obtuvo ninguna significación. En el $81 \%$ y $85 \%$ de los dos grupos se obtuvieron unos flujos de sangre $>275 \mathrm{ml} / \mathrm{min}$.

Todos los pacientes del grupo de heparina necesitaron algún tipo de manipulación ( 3 catéteres invertidos, 8 cambios posturales, 6 lavados con suero y 3 perfusión con uroquinasa), mientras en el grupo de citrato hubo 7 pacientes que no precisaron ningún tipo de manipulación, 6 tuvieron que invertirse, 1 precisó cambio postural y 8 fueron lavados con suero (figura 2). Ningún paciente precisó fibronolíticos.

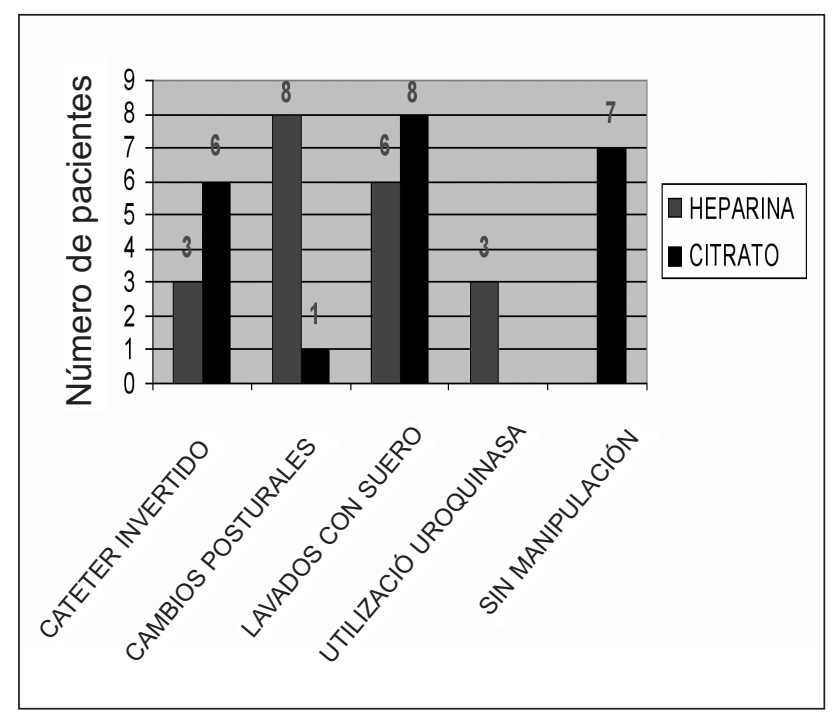

Figura 2. Manipulaciones cateter

En los pacientes que se cebaron con citrato observamos que la cantidad recomendada por el fabricante de los catéteres para el sellado es ligeramente inferior a las necesidades reales que se precisan para obtener un adecuado funcionamiento del catéter. Nuestra experiencia nos ha llevado a aumentar ligeramente el citrato de 0,1 a 0,2 ml, según la longitud del catéter, mediante perfusión muy lenta hasta conseguir los primeros signos de disgeusia (figuras 3 y 4 ).

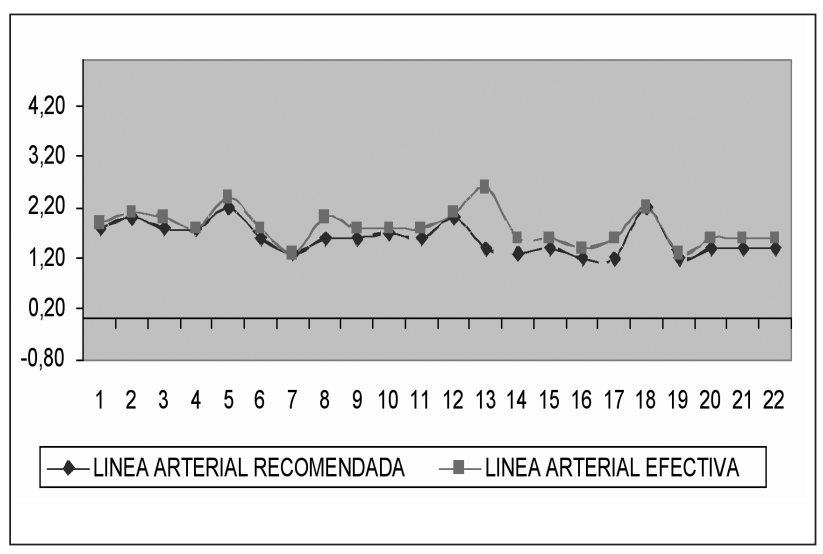

Figura 3. Variaciones del sellado con citrato del cateter (Arterial)

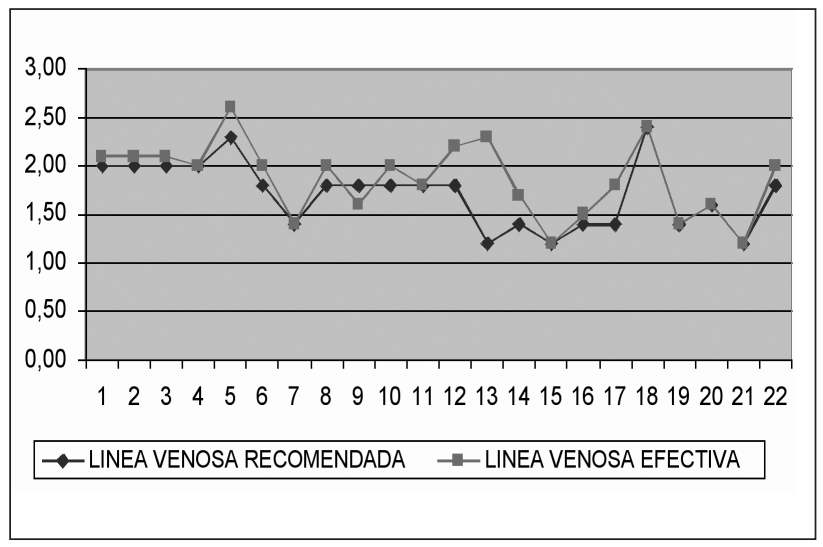

Figura 4. Variaciones del sellado con citrato del cateter (Venoso)

\section{Infecciones}

En el grupo de pacientes sellados con citrato, 19 $(86,36 \%)$ no tuvieron infecciones frente a los 9 $(45 \%)$ con heparina. En el grupo de citrato, 3 $(13,64 \%)$ tuvieron infección frente a 11 (55\%) del grupo de heparina (figura 5).

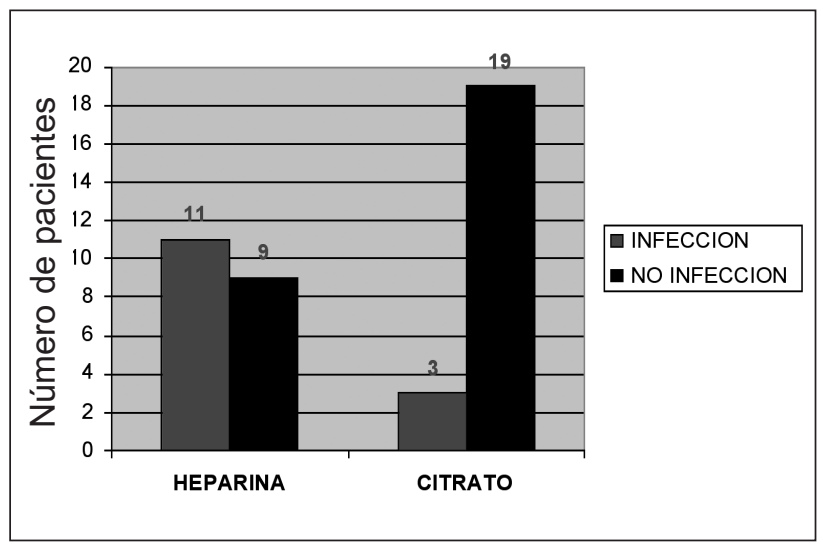

Figura 5. Infecciones 
De los 3 pacientes infectados en el grupo de citrato, 2 tuvieron infección del orificio y 1 del catéter. Dos de ellos llevaban catéter tunelizado y 1 llevaba catéter percutáneo. Un paciente precisó antibioterapia sistémica y el resto local.

De los 11 pacientes con infecciones del grupo de heparina, 10 fueron localizados en el orificio y 1 en el túnel. Diez pacientes llevaban catéteres percutáneos y 1 tunelizado. De estos, 5 necesitaron antibioterapia sistémica y 4 antibióticos locales y en 2 no se pudo registrar el tipo de antibioterapia.

\section{Motivo de la retirada del catéter}

Durante el estudio se retiraron 9 catéteres en ambos grupos por iniciar punción FAVI. Por disfunción se tuvieron que retirar 2 catéteres temporales en el grupo de citrato y 4 en el grupo de heparina. En el grupo de citrato se tuvo que retirar 1 catéter por infección; tenemos que hacer referencia que este paciente era parapléjico afectado de pluripatología asociada (artritis infecciosa portador de MRSA crónico) y en fase de caquexia.

\section{Eficacia de la diálisis}

En el grupo de los 22 pacientes sellados con citrato se estudió la eficacia dialítica valorando los siguientes parámetros: hemoglobina, fósforo, PCR, albúmina, KTV y el tiempo de tratamiento en minutos (tabla 1).

\begin{tabular}{|l|c|c|c|c|c|c|c|}
\hline \multicolumn{7}{|c|}{ Eficacia de la diálisis durante el estudio } \\
\hline Parámetro & Hb gr\% & PCR & KTV & P & Alb & TS \\
\hline Mediana & 11,29 & 6,00 & 1,41 & 4,62 & 37,10 & 240 \\
\hline
\end{tabular}

TS: tiempo tratamiento en minutos

Tabla 1.

\section{Discusión}

El sellado de los catéteres con citrato de alta concentración ha sido efectivo para reducir las infecciones y las disfunciones de los catéteres en nuestro servicio. Aunque la muestra de pacientes no es demasiado grande esperamos poder ampliar el estudio con resultados más significativos a lo largo de los próximos años utilizando dicho producto. No han aparecido problemas secundarios del producto, sólo una ligera disgeusia probablemente provocada por el paso al torrente circulatorio de una pequeña cantidad del producto como valor intencionado para asegurar la cantidad suficiente del sellado.

Este sistema nos puede limitar las resistencias y sensibilizaciones a los antibióticos, criterio importante ya que muchas veces estos son imprescindibles para tratar la pluripatología a largo plazo de estos pacientes.

Por otra parte, ante una indicación de diálisis sin heparina podemos optimizar mejor la indicación y minimizar los problemas de sangrado postratamiento (intervenciones quirúrgicas, angiodisplasia, menstruación, caídas fortuitas, etc) y evitar punciones de venas periféricas para extracciones analíticas de coagulación (Quick, Cefalina), práctica cada vez más común debido a la patología cardiovascular de estos pacientes.

Por último resaltar que así es posible disminuir los costes económicos a medio y a largo plazo, reduciendo antibióticos, fibronolíticos y las cargas de enfermería y a su vez, aumentar la calidad de la práctica del tratamiento.

\section{Bibliografía}

1. Ash SR, Mankus RA, Sutton JM et al. Concentrated Sodium Citrate for Catheter Lock. Hemodialysis International 2000; 4:22-31.

2. Baucells JM, Carbonell M, Palau MJ, Vives A. Eficacia de las maniobras de enfermería en la disfunción de los catéteres Perm-Cath®. Rev Soc Esp Enferm Nefrol 2003; 6 (2):15-18.

3. Bayés B, Bonal J, Romero R. Sodium citrate for fiIling haemodialysis catheters. Nephrology Dialysis Transplantation 1999; 14:2532.

4. Berns JS, Tokars JI. Preventing Bacterial Infections and Antimicrobial Resistance in Dialysis Pa- 
tients. American Journal of Kidney Diseases 2002; 40 (5): 886-898.

5. Donlan RM. Biofilms and Device-Associated Infections. Emerging Infectious Diseases 2001; 7 (2).

6. Moya Mejía M, Fernández Ros J, Ibeas López N et al. Monitorización sistemática del catéter permanente: una herramienta útil en el estudio de la tasa de infección y disfunción en dos tipos de catéteres tunelizados para hemodiálisis. Rev Soc Esp Enferm Nefrol 2006; 9 (3): 158-163.

7. Weijmer MC, Debets-Ossenkopp YJ, van de Vondervoort $\mathrm{FJ}$ et al. Superior antimicrobial activity of trisodium citrate over heparin for catheter locking. Nephrology Dialysis Transplantation 2002; 17:2189-2195.

8. Weijmer MC, van den Dorpel MA, van Geelen JA et al. Reduction of bleeding complications with high concentration trisodium citrate for hemodialysis catheter locking. A prospective multicenter double-blind randomized controlled trial. Nieuwsbrief van de NFN 2003; 6 (1).

9. Weijmer MC, van den Dorpel MA et al. Substantial reduction of infectious complications in hemodialysis catheters with trisodium citrate $30 \%$ for catheter locking. A prospective multicenter double-blind randomized controlled trial. Nieuwsbrief van de NFN 2003; 6 (1).

\section{Recursos en Internet:}

Sociedad Española de Nefrología:

Guías de Acceso Vascular en Hemodiálisis.

http://www.senefro.org/modules/subsection/files/gu ia_acceso_vascular.pdf http://www.citra-lock.com/pl.htm http://www.citra-lock.com/pl2.html http://www.citra-lock.com/pl3.html 